\title{
Prediction of Rheological Properties and Interfacial Tension of Mixtures of Immiscible Polypropylene-Polystyrene (PP3/PS) Blends
}

\author{
Meriem BOUDOUKHANI ${ }^{1, *}$, Nadji MOULAI-MOSTEFA ${ }^{1}$ and Salim HAMMANI ${ }^{2}$
}

${ }^{I}$ Material and Environmental Laboratory, University of Medea, Medea, Algeria

${ }^{2}$ LAFPC, University of Blida, Blida, Algeria

('Corresponding author's e-mail: mboudekani@yahoo.fr)

Received: 25 November 2016, Revised: 21 July 2018, Accepted: 9 August 2018

\begin{abstract}
Blends of polypropylene (PP3) and polystyrene (PS) were studied and, their rheological behavior was determined and discussed in detail. The interfacial tension between the blend components was evaluated from the rheological data and the storage modulus by using two well-known models: Palierne model and Choi-Schowalter equation. The theoretical predictions were compared with experimental data obtained from PP3/PS blends. The obtained results showed that the Palierne model could predict the rheological and viscoelastic properties of the considered polymer blends. In addition, the interfacial tensions between PP3 and PS were evaluated and compared with those cited in the literature. It was also found that the Palierne model was more accurate than Choi-Schowalter one in determining the interfacial tension.
\end{abstract}

Keywords: Polypropylene-Polystyrene blend, Palierne model, Choi-Schowalter equation, Interfacial tension, Linear viscoelasticity

\section{Introduction}

Blending of polymers is an effective way to obtain new materials with improved characteristics [1]. Due to the ability to combine the properties of their components in a single product, the polymer blends have been used for the development of new materials in many industrial areas [2]. However, most polymer blends are incompatible due to the existence of interfacial tensions between their phases [3,4].

The rheological properties of molten components in immiscible polymer blends affect the processing, morphology and relationship between their characteristics [5]. The qualities of the obtained blends are mainly determined by the viscoelastic properties of their components and are sensitive to the changes in morphology. The flow itself depends on the two important rheological properties, namely the high value in polymer viscosity in a molten state and, the elastic behavior. In addition, the viscoelastic character is a frequent non-Newtonian behavior in the polymer blends. The response of fluid to a deformation presents, at the same time, elastic and viscous aspects. Generally, studies are carried out within the framework of linear viscoelasticity where the morphology is not affected by the flow [6-8].

It is possible to use theoretical approaches to predict the rheological behavior of the polymer blends. Several authors have modeled the rheological behavior of the blends by identifying them to emulsions (matrix/disperse phase). Einstein [9] assumed that the suspension was much diluted thereby neglecting the interactions between particles. Oldroyd [10] described the behavior of dilute suspensions by including a constant interfacial tension. This description was reported earlier by Choi and Schowalter [11].

The Palierne model [12] is an extension of the Oldroyd model. This model also takes into account the effects of the size distribution of inclusions. It describes the complex modulus of the mixture from those of the dispersed phase and matrix. It was also used for the prediction of the linear viscoelastic behavior of polymer emulsions. Bousmina and Muller [13] simplified the model of Palierne for a 
http://wjst.wu.ac.th

monodisperse distribution of inclusions, using the mean diameter by volume. Graebling et al. [14] studied the immiscible polymer blends with and without interfacial agent. They have applied this model to mixtures such PS/PMMA and PDMS/POE. A good agreement between the experimental results and the simplified Palierne model was obtained. Lacroix et al. [15] used the Palierne model to estimate the viscoelastic data and interfacial tension. This model was also used successfully to predict the rheological behavior of some blends at different temperatures and compositions. Carreau et al. [16] confirmed experimentally the applicability of this model for PS/PMMA and PA/PP systems, respectively. Kunyawut and Hermes [17] used the Palierne model to describe the Rheological Behavior of Immiscible PS/LDPE Blends. Romoscanu et al. [18] employed the Palierne model to describe the rheological behaviorof lowviscous emulsions; their experimental results were compared with those deduced from the Palierne model predictions. The Palierne model has also been successfully used to indirectly measure the interfacial tension between several polymers [16,19-21]. Carreau et al. [16] compared the experimental results with theoretical model predictions and confirmed the results for PS/PE blends. Unlike to Palierne model, the model of Choi-Schowalter [11] did not arouse too much excitement despite the research giving good results as for Palierne predictions with specific and comparable terms. This model is applicable to polymer blends at low frequency where the blend components behave as viscous liquids. Scholz et al. [22] demonstrated the validity of this model for PP/PA blends at low frequencies. This model was applied to PS/PMMA and emulsified SAN/PS blends in much wider frequency ranges [23].

The interfacial tension of the compatibilized SAN/EPDM blend was determined from the morphological studies [16] and the relaxation time was calculated using the Palierne and Choi-Schowalter models. The predictions of the Choi-Schowalter model are not very different from those of the Palierne model at low frequencies. Recently, Jose et al. [24] employed the Palierne and Choi-Schowaltermodels to calculate the interfacial tension. It was found that the rheological properties of both compatibilized and uncompatibilized blends are intimately related to their phase morphology. On the other hand, the interfacial tension between PLA and PETG was determined from morphological characteristics and viscoelastic responses of blends using Palierne and G-M models. Khonakdar et al. [25] studied the viscoelastic properties as melt and solid state of COC/POE blends using Palierne and G-M models. They observed a good agreement between the experimental results and those predicted by the Palierne model. Dil and Favis [26] studied the morphology and miscibility of PLA and PBAT blends. They examined the interfacial tension of the studied system by fitting the Palierne model to the rheological data. Kwon and Cho [27] have determined the viscoelasticity of immiscible polymers blends by relaxation of the interface using the Palierne and G-M models; they calculated the storage modulus of immiscible blends and obtained the weighted relaxation time spectra of them.

The aim of this paper is to determine whether the models proposed by Paliern and Choi-Schowalter can be used for the evaluation of viscoelastic properties and interfacial tension for a polymer blend formed by polypropylene and polystyrene (PP/PS, 30/70 wt/wt).

PP is one of the most widely used polymers owing to its advantages such as low cost and density, easy processing and good chemical resistance. However, it presents some limitations because of its relatively poor impact resistance; on the other hand, PS has many desirable properties, but its disadvantages are low impact strength and poor chemical resistance at room temperature [28]. Thus, blending of PS with PP can be a convenient way to increase the impact strength and chemical resistance of PS. PS/PP blends seem to be promising materials for various purposes in packaging and for components that need improved chemical resistance [29].

The determination of the viscoelastic behaviour of polymer blends is of particular importance because it is in this area that will be processed such materials. In addition, the macroscopic strains involved during the formatting correspond to the nonlinear viscoelasticity, which is an important source of information about the structure of macromolecules and their rheological behaviour [30]. For a viscoelastic system, the elasticity of the two phases is a criterion in the mixing operation. In general, it is very difficult to deform an elastic phase in a non-elastic phase [31].

The rheological behavior of the blends was studied by small amplitude oscillatory shear and correlated to the morphological observations. The interfacial tension between the blend components was 
http://wjst.wu.ac.th

evaluated from the rheological data. In addition, the influence of the temperature on the viscoelastic parameters and interfacial tension was evaluated. The predicted results were compared with those obtained experimentally in a previous study on such system.

\section{Materials and methods}

Materials

The materials used in this study were of commercial grades. Standard polystyrene (PS) was supplied by BASF S.A (Germany); it has an average molecular weight of $215,160 \mathrm{~g} / \mathrm{moland}$, a polydispersity coefficient of 2.35. Isotactic polypropylene (PP) was purchased from INEOS Company (Switzerland); it has a melt flow index (MFI) of $0.9 \mathrm{~g} / 10 \mathrm{~min}$ and adensity of $0.923 \mathrm{~g} / \mathrm{cm}^{3}$.

\section{Preparation of polymer blends}

PS (matrix) is an amorphous polymer with a glass transition temperature of the order of $100{ }^{\circ} \mathrm{C}$. In contrast, $\mathrm{PP}$ is a semi-crystalline polymer; its melting temperature is of the order of $165{ }^{\circ} \mathrm{C}$. This difference between these two temperatures made it possible to freeze the dispersed phase while keeping the matrix in a fluid state. The polymer granulates were pre-mixed and injected in the twin screw mini extruder (Thermo Haake) at $200{ }^{\circ} \mathrm{C}$. Samples were blended for $3 \mathrm{~min}$ at $200{ }^{\circ} \mathrm{C}$ and $60 \mathrm{rpm}$, followed by a rapid change of the extrusion speed while keeping the same temperature. After $3 \mathrm{~min}$, the cooling phase was started, maintaining the speed extrusion to the point of crystallization of the dispersed phase, in order to freeze the generated microstructures.

\section{Scanning electron microscopy}

A Hitachi S-3340 scanning electron microscopy (SEM), operating at $15 \mathrm{KV}$ accelerating voltage, was used to observe the blend morphology. The surfaces taken from cryofractured samples were observed by SEM. After drying procedure, the samples were coated with goldpalladium thick film. The adopted technique to detect the morphological evolution was based on an image of the sample on two-dimensional (2D) object, because the fibrillar morphology can be viewed as droplets when the fibrils are observed perpendicularly to the flow direction.

\section{Rheological measurements}

The rheological characterization of the pure and polymer blends was realized in a previous study conducted by Hammani[32] using a stress controlled rheometer (RS 100) from Thermo HaakeRheostress, using parallel plate geometry (diameter $20 \mathrm{~mm}$ and a gap of $1 \mathrm{~mm}$ ). Samples with $20 \mathrm{~mm}$ and a thickness of $1 \mathrm{~mm}$ were compression molded from the test material using hydraulic press (Carven-USA) at $200{ }^{\circ} \mathrm{C}$. For all measurements, the stress amplitude was fixed at $10 \mathrm{~Pa}$ to insure the viscoelastic linearity of the response. All material functions were determined in the frequency range from 0.001 to $10 \mathrm{~s}^{-1}$. The temperatures selected for the investigation were between 170 and $220{ }^{\circ} \mathrm{C}$. This choice is based on the thermal properties of each constituent; it varies between the glass transition temperature of PS and the melting point of PP3.

\section{Emulsion models}

\section{Palierne model}

Several models have been proposed to describe either the deformation of the dispersed phase or to derive rheological parameters such as the complex shear modulus;

$G^{*}(w)=G^{\prime}(w)+j G^{\prime \prime}(w)$

To better provide a general understanding of the approach used in this paper, a brief description of Palierne model is given [12]. This model treats the linear rheology of an emulsion of viscoelastic incompressible fluids experiencing small amplitude oscillatory shear flow. It gives a general expression 
of the complex shear modulus of the emulsion taking into account particle size, particle nature polydispersity, shear and dilatation of the interface.

For the simple case of an emulsion of two viscoelastic polymers, Eq. (1) can be written as [12]:

$\mathrm{G}_{\mathrm{b}}^{*}(\omega)=\mathrm{G}_{\mathrm{m}}^{*}(\omega) \frac{1+3 \sum_{\mathrm{i}} \phi_{\mathrm{i}} \mathrm{H}_{\mathrm{i}}^{*}(\omega)}{1-2 \sum_{\mathrm{i}} \phi_{\mathrm{i}} \mathrm{H}_{\mathrm{i}}^{*}(\omega)}$

In this equation, $\mathrm{H}^{*}(\mathrm{w})$ is described by Eq. (3):

$\mathrm{H}_{\mathrm{i}}^{*}(\omega)=\frac{\left(8 \alpha / \mathrm{d}_{\mathrm{i}}\right)\left[2 \mathrm{G}_{\mathrm{m}}^{*}(\omega)+5 \mathrm{G}_{\mathrm{d}}^{*}(\omega)\right]+\left[\mathrm{G}_{\mathrm{d}}^{*}(\omega)-\mathrm{G}_{\mathrm{m}}^{*}(\omega)\right]\left[16 \mathrm{G}_{\mathrm{m}}^{*}(\omega)+19 \mathrm{G}_{\mathrm{d}}^{*}(\omega)\right]}{\left(80 \alpha / \mathrm{d}_{\mathrm{i}}\right)\left[\mathrm{G}_{\mathrm{m}}^{*}(\omega)+\mathrm{G}_{\mathrm{d}}^{*}(\omega)\right]+\left[2 \mathrm{G}_{\mathrm{d}}^{*}(\omega)+3 \mathrm{G}_{\mathrm{m}}^{*}(\omega)\right]\left[16 \mathrm{G}_{\mathrm{m}}^{*}(\omega)+19 \mathrm{G}_{\mathrm{d}}^{*}(\omega)\right]}$

where $G^{*}, G_{m}^{*}, G_{d}^{*}$ are the complex shear moduli of the blend, matrix, and dispersed phase, respectively; $\alpha$ is the interfacial tension between the components of the blend and $\emptyset_{\mathrm{i}}$ is the volume fraction of the droplets with a diameter di.

This model can be simplified by considering the monodisperse size. For that, an average diameter in volume $d_{v}$ (representative of the size distribution) is used.

The modules G' and G" can be expressed as:

$\mathrm{G}^{\prime}=\frac{1}{\mathrm{D}}\left[\mathrm{G}_{\mathrm{m}}^{\prime}\left(\mathrm{B}_{1} \mathrm{~B}_{2}+\mathrm{B}_{3} \mathrm{~B}_{4}\right)-\mathrm{G}_{\mathrm{m}}^{\prime \prime}\left(\mathrm{B}_{4} \mathrm{~B}_{1}-\mathrm{B}_{2} \mathrm{~B}_{3}\right)\right]$

$\mathrm{G}^{\prime \prime}=\frac{1}{\mathrm{D}}\left[\mathrm{G}_{\mathrm{m}}^{\prime}\left(\mathrm{B}_{4} \mathrm{~B}_{1}-\mathrm{B}_{2} \mathrm{~B}_{3}\right)+\mathrm{G}_{\mathrm{m}}^{\prime \prime}\left(\mathrm{B}_{1} \mathrm{~B}_{2}+\mathrm{B}_{3} \mathrm{~B}_{4}\right)\right]$

where the constants $\mathrm{B}_{1}, \mathrm{~B}_{2}, \mathrm{~B}_{3}, \mathrm{~B}_{4}$ and $\mathrm{D}$ are given by:

$\mathrm{B}_{1}=\mathrm{C}_{1}-2 \varphi \mathrm{C}_{3}$

$\mathrm{B}_{2}=\mathrm{C}_{1}+3 \varphi \mathrm{C}_{3}$

$\mathrm{B}_{3}=\mathrm{C}_{2}-2 \varphi \mathrm{C}_{4}$

$\mathrm{B}_{4}=\mathrm{C}_{2}+3 \varphi \mathrm{C}_{4}$

$\mathrm{D}=\left(\mathrm{C}_{2}-2 \varphi \mathrm{C}_{4}\right)^{2}+\left(\mathrm{C}_{1}-2 \varphi \mathrm{C}_{3}\right)^{2}$

with:

$\mathrm{C}_{1}=80 \frac{\alpha}{\mathrm{d}_{\mathrm{v}}}\left(\mathrm{G}_{\mathrm{m}}^{\prime}+\mathrm{G}_{\mathrm{d}}^{\prime}\right)+38\left(\mathrm{G}_{\mathrm{d}}^{\prime 2}-\mathrm{G}_{\mathrm{d}}^{\prime 2}\right)+48\left(\mathrm{G}_{\mathrm{m}}^{\prime 2}-\mathrm{G}_{\mathrm{m}}^{\prime 2}\right)+89\left(\mathrm{G}_{\mathrm{m}}^{\prime} \mathrm{G}_{\mathrm{d}}^{\prime}-\mathrm{G}_{\mathrm{m}}^{\prime \prime} \mathrm{G}_{\mathrm{d}}^{\prime \prime}\right)$

$\mathrm{C}_{2}=80 \frac{\alpha}{\mathrm{d}_{\mathrm{v}}}\left(\mathrm{G}_{\mathrm{m}}^{\prime \prime}+\mathrm{G}_{\mathrm{d}}^{\prime \prime}\right)+96 \mathrm{G}_{\mathrm{m}}^{\prime} \mathrm{G}_{\mathrm{m}}^{\prime \prime}+76 \mathrm{G}_{\mathrm{d}}^{\prime} \mathrm{G}_{\mathrm{d}}^{\prime \prime}+89\left(\mathrm{G}_{\mathrm{m}}^{\prime \prime} \mathrm{G}_{\mathrm{d}}^{\prime}+\mathrm{G}_{\mathrm{m}}^{\prime} \mathrm{G}_{\mathrm{d}}^{\prime \prime}\right)$

$\mathrm{C}_{3}=8 \frac{\alpha}{\mathrm{d}_{\mathrm{v}}}\left(2 \mathrm{G}_{\mathrm{m}}^{\prime}+5 \mathrm{G}_{\mathrm{d}}^{\prime}\right)-16\left(\mathrm{G}_{\mathrm{m}}^{\prime 2}-\mathrm{G}_{\mathrm{m}}^{\prime \prime 2}\right)+19\left(\mathrm{G}_{\mathrm{d}}^{\prime 2}-\mathrm{G}_{\mathrm{d}}^{\prime \prime 2}\right)-3\left(\mathrm{G}_{\mathrm{m}}^{\prime} \mathrm{G}_{\mathrm{d}}^{\prime}-\mathrm{G}_{\mathrm{m}}^{\prime \prime} \mathrm{G}_{\mathrm{d}}^{\prime \prime}\right)$

$\mathrm{C}_{4}=8 \frac{\alpha}{\mathrm{d}_{\mathrm{v}}}\left(2 \mathrm{G}_{\mathrm{m}}^{\prime \prime}+5 \mathrm{G}_{\mathrm{d}}^{\prime \prime}\right)-32 \mathrm{G}_{\mathrm{m}}^{\prime} \mathrm{G}_{\mathrm{m}}^{\prime \prime}+38 \mathrm{G}_{\mathrm{d}}^{\prime} \mathrm{G}_{\mathrm{d}}^{\prime \prime}-3\left(\mathrm{G}_{\mathrm{m}}^{\prime \prime} \mathrm{G}_{\mathrm{d}}^{\prime}+\mathrm{G}_{\mathrm{m}}^{\prime} \mathrm{G}_{\mathrm{d}}^{\prime \prime}\right)$

From Eqs. (4) and (5), it is possible to predict the viscosity using the Palierne model.

$\eta^{*}(\omega)=\eta^{\prime}(\omega)-i \eta^{\prime \prime}(\omega)$

where:

$\eta^{\prime}(\omega)=\frac{\mathrm{G} \prime \prime}{\omega}$ and $\eta^{\prime \prime}(\omega)=\frac{\mathrm{G} \prime}{\omega}$

Thus, once G' and G" are already calculated, the viscosity can be then determined. 


\section{Choi-Schowalter model}

The purpose of Choi-Schowaltermodel [11], developed for a mixture of two Newtonian fluids, is to predict the dynamic behavior of a mixture. The following equations give the storage modulus and the loss modulus of a mixture of polymers:

$$
\begin{aligned}
& G^{\prime}(\omega)=\emptyset G_{d}^{\prime}(\omega)+(1-\emptyset) G_{m}^{\prime}(\omega)+\frac{\eta}{\tau_{1}}\left(1-\frac{\tau_{2}}{\tau_{1}}\right) \frac{\omega^{2} \tau_{1}^{2}}{1+\omega^{2} \tau_{1}^{2}} \\
& G^{\prime \prime}(\omega)=\varnothing G_{d}^{\prime \prime}(\omega)+(1-\emptyset) G_{m}^{\prime \prime}(\omega)+\frac{\eta}{\tau_{1}}\left(1-\frac{\tau_{2}}{\tau_{1}}\right) \frac{\omega \tau_{1}}{1+\omega^{2} \tau_{1}^{2}}
\end{aligned}
$$

where:

$\eta=\eta_{m}\left(1+\emptyset \frac{(5 K+2)}{2(K+1)}+\emptyset^{2} \frac{5(5 K+2)^{2}}{8(K+1)^{2}}\right)$

and:

$\tau_{2}=\tau_{0}\left(1+\emptyset \frac{3(19 K+16)}{4(k+1)(2 K+3)}\right)$

$\tau_{1}=\tau_{0}\left(1+\emptyset \frac{5(19 K+16)}{4(k+1)(2 K+3)}\right)$

$\tau_{0}=\frac{\eta_{\mathrm{m}} \mathrm{R}}{\alpha} * \frac{(19 \mathrm{~K}+16)(2 \mathrm{~K}+3)}{40(\mathrm{k}+1)}$

In these equations, the constant $\mathrm{K}$ is given by:

$\mathrm{K}=\eta_{\mathrm{d}} / \eta_{\mathrm{m}}$

where $\eta, \eta_{\mathrm{m}}, \eta_{\mathrm{d}}$ are the blend, matrix and disperse phase Newtonian viscosities, respectively; $\alpha$ is the interfacial tension; $\mathrm{R}$ is the average radius and $\emptyset_{\mathrm{i}}$ is the volume fraction of the dispersed phase.

The term $\tau_{i}$ corresponds to the relaxation time of the blend due to the relaxation of the interface between the blend components. The blend relaxation spectrum is a combination of the relaxation spectra of the different phases of the blend and an additional peak $\tau_{1}$, from which the interfacial tension between the components of the blends can be inferred.

\section{Results and discussion}

Morphology and thermal properties of the polymer blend

Figure 1 shows the microscopic images of PS/PP blends (70/30, wt/wt). The blend exhibited heterogeneous phase-separated morphology which was like droplets in the matrix. The observed cavities corresponding to the footprints of PP nodules indicated poor adhesion between PP (dispersed phase) and PS (matrix). The formation of such microstructure resulted from the competition between coalescence and breakup of the dispersed phase induced by the action of shear during melt mixing or by slipping of the PP phase in the PS matrix [33].

Otherwise, the matrix (PS) presented a glace transition temperature of about $96{ }^{\circ} \mathrm{C}$ and, PP (dispersed phase) presented a melting and crystallization temperatures of 165 and $112{ }^{\circ} \mathrm{C}$, respectively [32]. These parameters are valuable information in order to distinguish difference between the crystallization of the dispersed phase and the glass transition of the matrix temperatures. 
http://wjst.wu.ac.th

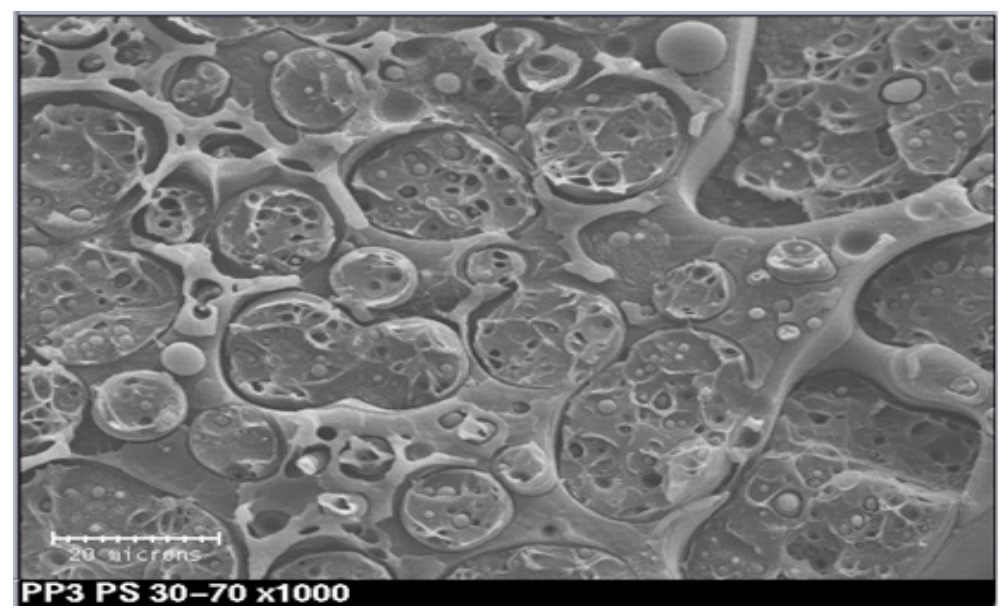

Figure 1 Micrographs of the blend formed by PP3/PS (30/70, \% in wt.) with a resolution $(\times 1000)$.

\section{Rheology analysis}

Initially, the rheological identification of the storage $\left(G^{\prime}\right)$ and loss $\left(G^{\prime \prime}\right)$ moduli for the whole of PP3 and PS was studied. Figure 2 shows the variation of both $G^{\prime}$ and $G^{\prime \prime}$ as a function of frequency. In order to get a general idea on the rheological behaviour of pure polymers during the extrusion phase, the experiments were performed at the same extrusion temperature $\left(180{ }^{\circ} \mathrm{C}\right)$. A dependence was observed between the elastic modulus and the frequency; $\mathrm{G}^{\prime}$ increases with increasing frequency. It was also observed that PS is highly elastic compared to PP. We note also that for high frequencies $\mathrm{G}^{\prime}$ is greater than $G^{\prime \prime}$ in the case of PS; however for PP, plastic behavior is less important since $G^{\prime \prime}$ is greater than $G^{\prime}$ for frequency values less than $10 \mathrm{~Hz}$. From this frequencyvalue, $G^{\prime \prime}$ is equivalent to $\mathrm{G}^{\prime}$. It is why PP is dispersed in PS.
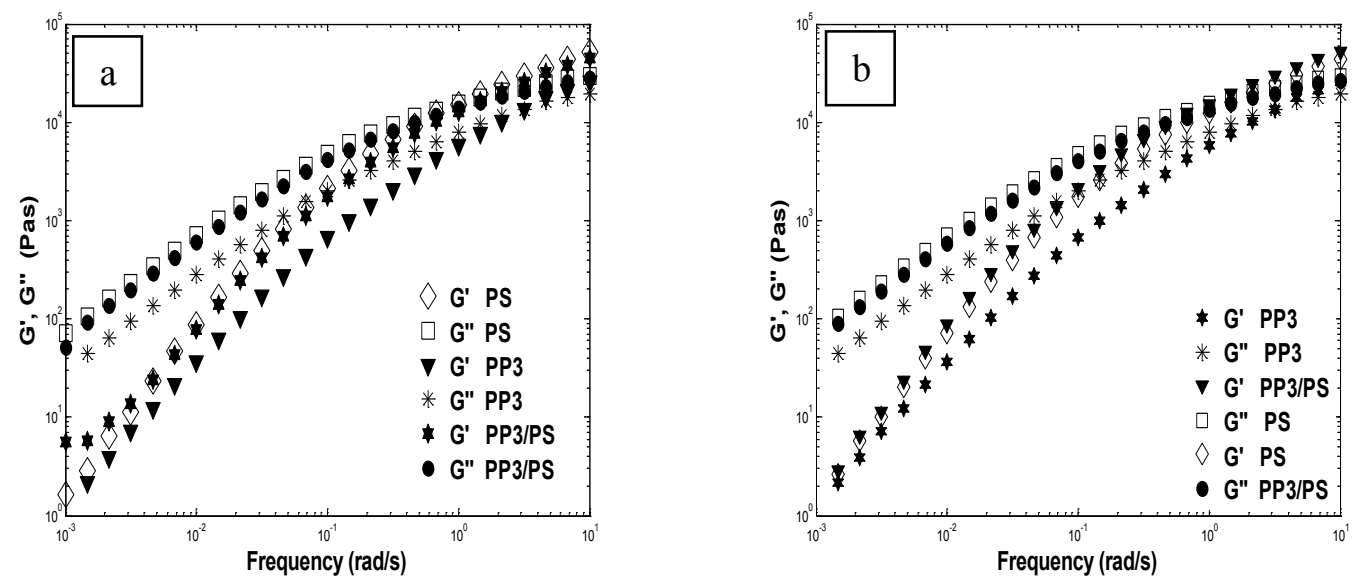

Figure 2 Effect of addition of the dispersed phase on the evolution of elastic and loss modules at $180{ }^{\circ} \mathrm{C}$ (a) Palierne Model; (b) Choi-Schowalter equation. 
http://wjst.wu.ac.th

The addition of PP3, like a dispersed phase in the matrix PS, leads to an increase in the rheological properties of the mixture. All of the storage and loss moduli for PP3/PS (30/70) blend obtained by Palierne model and Choi-Schowalter equation at a constant temperature $\left(180{ }^{\circ} \mathrm{C}\right)$ were illustrated in Figures 2a and $\mathbf{2 b}$, respectively. It was noticed that the values of $G^{\prime}$ and $G^{\prime \prime}$ of the blend are equivalent to those of PS. It is clear from these results that the viscoelastic properties of the matrix control those of the blend. Moreover, a shoulder was observed in the curve of the elastic character $\left(\mathrm{G}^{\prime}\right)$ in the zone of low frequencies $\left(10^{-3}-10^{-2} \mathrm{rad} / \mathrm{s}\right)$. This increase in elasticity was allotted to the deformability of droplets, and by consequence, the viscous character was dominating, explaining the fact that the values of $G^{\prime \prime}$ were larger than those of G'. For large values of frequency, the difference between the storage modulus curve of the blend and matrix was not large enough to allow the occurrence of a secondary plateau [34]. Curves giving the evolution of the rheological properties using the Choi-Schowalter equation for PP3, PS and PP3/PS (30/70) blend are presented in Figure 2b. The analysis of the results showed that the elastic and loss modules of the blend were very close to the properties of the matrix (PS), confirming the precedent results. However, the shoulder did not appear in comparison with the results predicted by the Palierne model.

Effects of temperature on the elastic properties were performed on a mixture PP3/PS at different temperatures $\left(170,180,200\right.$ and $220^{\circ} \mathrm{C}$ ). When the Palierne model is used (Figure 3a), it was observed that the increase in temperature reduces $G^{\prime}$ for the whole frequency range. We also note that the slope of the elasticity curve of the mixture changes as the temperature increases. This phenomenon is very interesting in the cooling phase of mixtures in the mini-extruder, which gives an opportunity to save the morphology generated during extrusion [32]. At $200{ }^{\circ} \mathrm{C}$, the shoulder of $\mathrm{G}^{\prime}$ at low frequency does not appear, confirming the role of the deformability of inclusions. This figure makes it possible to visualize a good shoulder on the evolution of the elastic modulus. The rheological behavior of the blend is directly influenced by the properties of the matrix PS. These results confirm that the matrix is more viscous than the dispersed phase.In the case of Choi-Schowalter model (Figure 3b), we note for low frequencies that the increase in temperature leads to a decrease of $\mathrm{G}^{\prime}$; however for high frequencies the temperature seems to have a little effect on the viscoelastic properties. In addition, it was observed the presence of a shoulder on the curve $G^{\prime}$ at high temperatures; this indicates the relieving of the dispersed phase. This shoulderdisappearswhen the temperature decreases.
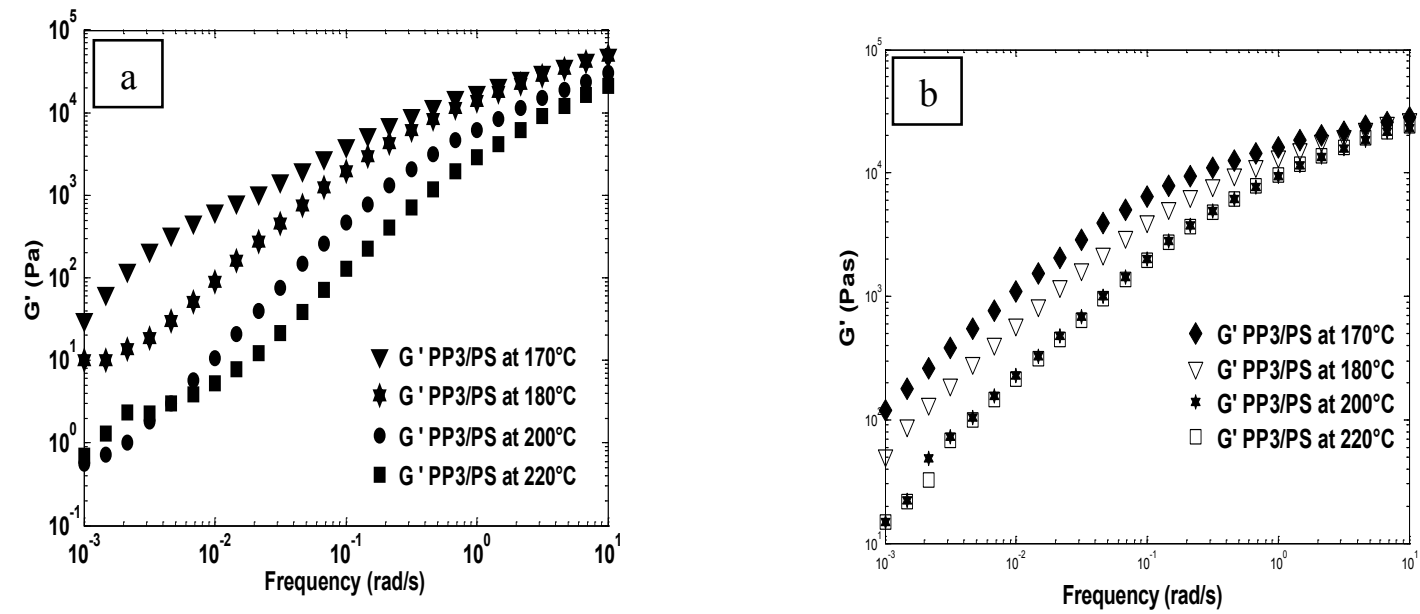

Figure 3 Storage and loss modulus for PP3/PS blend predicted at different temperatures; (a) Palierne model $\left(\mathrm{R}_{0}=4.85 \mathrm{E}-04 \mathrm{~m}, \emptyset_{\mathrm{i}}=0.3, \alpha=6.25 \mathrm{mN} / \mathrm{m}\right.$ and $\left.\tau_{0}=14.677 \mathrm{~s}\right)$, (b) Choi-Schowalter equation $\left(\mathrm{R}_{0}\right.$ $=7.78 \mathrm{E}-04 \mathrm{~m}, \emptyset_{\mathrm{i}}=0.3, \alpha=6.25 \mathrm{mN} / \mathrm{m}$ and $\tau_{0}=12.378 \mathrm{~s}$ ). 


\section{Viscosity measurements}

Figures $4 \mathbf{a}$ and $\mathbf{4 b}$ show the variation of the complex viscosity predicted by the Palierne model and Choi-Schowalter equation as a function of frequency for native polymers (PP and PS) and for blend (PP/PS), respectively. It was noted in the two cases that the increase in frequency decreases the complex viscosity. This result is attributed to the shear thinning behavior associated to the blend and its constituents. PS has the highest viscosity, against PP which is characterized by the lower viscosity. The addition of PP in PS matrix increases the viscosity of the mixture throughout the frequency range. The reason may be due to the high level of immiscibility which increases the sensitivity of the mixture to fluctuations in frequency. Thus, in all cases, a pseudo plastic behavior was observed. It was also noticed that PS has the maximum while PP3 has the minimum complex viscosity in the whole range of frequency at $180{ }^{\circ} \mathrm{C}$. The emulsion formed with $30 \%$ of PP3 and $70 \%$ of PS has a viscosity higher than that of the two components forming the blend.
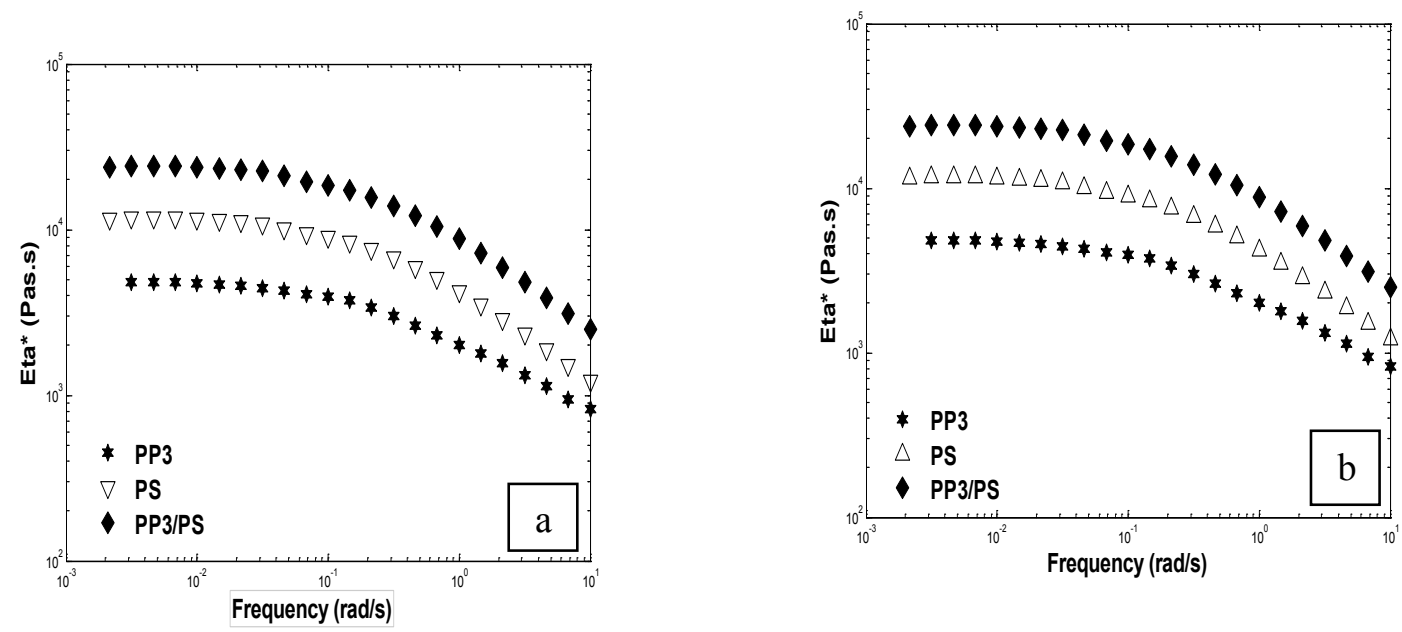

Figure 4 Evolution of complex viscosity as a function of frequency at $180{ }^{\circ} \mathrm{C}$; (a) Palierne Model, (b) Choi-Schowalter equation.

The variations of the complex viscosities of the blend (PP3/PS, 30/70) at different temperatures are illustrated in Figure 5a (Palierne model) and in Figure 5b (Choi-Schowalter equation). From the obtained results, it was shown that when the frequency increases, the complex viscosity decreases. Further, with the increase in frequency, the relaxation time decreases or in other, the shear rate increases.

Thus, an increase in frequency has the same effect as that of the increase in shear rate. In addition, the increase in temperature leads to a decrease in viscosity of the blend in all cases.

Furthermore, at temperatures of 200 and $220{ }^{\circ} \mathrm{C}$, the blend records the lowest viscosity compared to the two components forming the blend (Figure 5). This can occur because of the elevated level of immiscibility, which increases the sensitivity of the blend to the fluctuations of the frequency. It indicates that this blend is represented by the negative law deviation blend (NDB). At low frequencies, a negative deviation behavior of the complex viscosity was noticed, which probably originate in slip at the interface due to poor or insufficient adhesion between the matrix and dispersed phase [34]. It should be noted that the viscosity difference between the polymers has a significant impact on the phase morphology of blends.

The obtained results showed that the complex viscosity evolves inversely proportional to the temperature. Dagli and Kamdar [35] studied the viscosity variation based on the ratio PP3/PS at different temperatures. They noticed that this ratio changes as a function of shear rate whatever the temperature. 

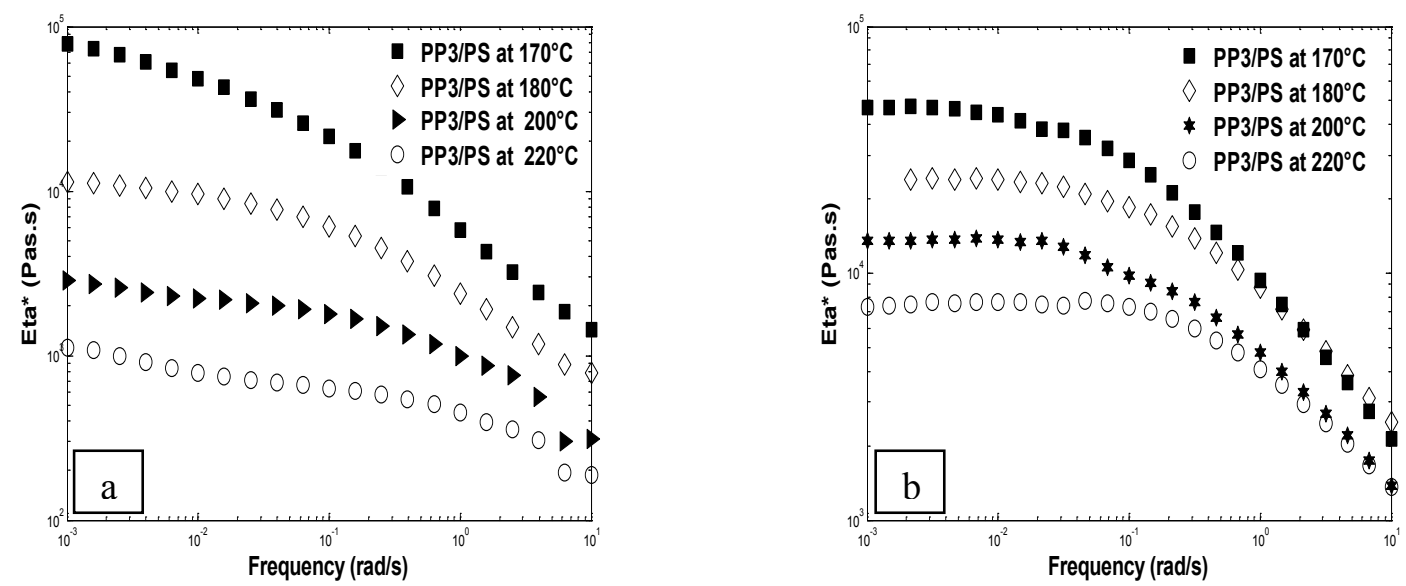

Figure 5 Effects of temperature on the variation of complex viscosity versus frequency at $180{ }^{\circ} \mathrm{C}$, (a) Palierne Model, (b) Choi-Schowalter equation.

\section{Comparison of model predictions with experimental data}

In order to validate the rheological properties deduced from the predictive models, the obtained results were compared with those obtained experimentally in a previous study [32]. The evolution of the predicted and experimental results is shown in Figure 6a for the variation of the elastic modulus and Figure $\mathbf{6 b}$ for the variation of the complex viscosity, respectively.
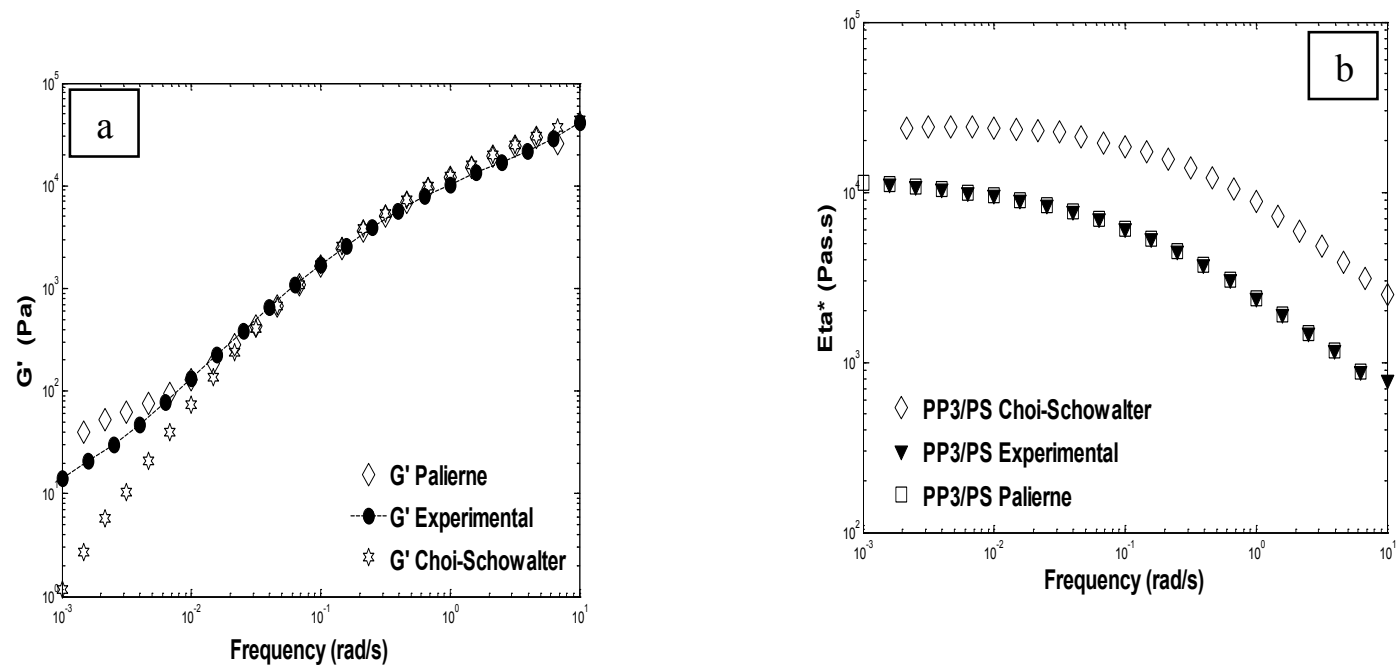

Figure 6 Comparison between experimental and predicted results of G' for the blend PP3/PS (30/70) at $180^{\circ} \mathrm{C}$; (a): G', (b): Complex viscosity. 
http://wjst.wu.ac.th

It was noticed that the results predicted by the Palierne model are in agreement with the experimental results and the superposition is almost perfect for the storage modulus or for the loss modulus (Figure 6a). Contrary to the Palierne model, we note a difference in the elasticity values when the Choi-Schowalter equation is used, mainly in the region of low frequencies $\left(10^{-3}-10^{-2} \mathrm{~s}^{-1}\right)$ and is superimposed beyond.

Furthermore, the prediction of the complex viscosity by the Palierne model seems to be perfect where the curves representing the variations of the complex viscosity versus frequency are superposed (Figure 6b), while the values of viscosity predicted by the equation of Choi-Schowalter are different in comparison with experimental results.

\section{Interfacial tension measurements}

The majority of theory showed that more polymers will be immiscible, implying that the interfacial tension will be important [36], hence, the incorporation of a polymeric phase in a polymeric matrix appreciably modified the viscoelastic properties of the matrix.

The interfacial tension $(\alpha)$ between polymers in a molten state is calculated using the Paliernemodel (Eq. (13)) or Choi-Schowalter equation (Eq. (14)).

$\alpha=\left[\frac{R_{v} \eta_{m}}{4 \tau}\right]\left[\frac{(19 K+16)(2 K+3-2 \emptyset(K-1))}{(10(K+1))-(2 \varnothing(5 K+2))}\right]$

$\alpha=\left[\frac{R_{v} \eta_{m}}{\tau}\right]\left[\frac{(19 K+16)(2 K+3)}{(40(K+1))}\right]\left[1+\emptyset\left\{\frac{5(19 K+16)}{(4(K+1))(2 K+3)}\right\}\right]$

where $\eta_{\mathrm{m}}$ isthe viscosity of the matrix, $\varnothing$ is the fraction volume of dispersed phases, $\mathrm{K}$ is the viscosity ratio.

The predicted results of interfacial tensions of blends using the Palierne and Choi-Schowalter models are summarized in Table 1.

Table 1 Evolution of the interfacial tension with temperature.

\begin{tabular}{ccc}
\hline \multirow{2}{*}{ Temperature $\left({ }^{\circ} \mathbf{C}\right)$} & \multicolumn{2}{c}{ Interfacial tension $(\mathbf{m N} / \mathbf{m})$} \\
\cline { 2 - 3 } & Paliernemodel's values & Choi-Showaltermodel's values \\
\hline 170 & 5.6 & 3.6 \\
200 & 5.6 & 3.5 \\
220 & 5.4 & 3.5 \\
& 4.4 & 3.5 \\
\hline
\end{tabular}

Analysis of the obtained results derived from the Palierne model shows that the interfacial tension is not accompanied by the reduction of the size of the dispersed particles. A reduction was noted when the temperature is increased; a value of $5.6 \mathrm{mN} / \mathrm{m}$ was obtained at a temperature of $180{ }^{\circ} \mathrm{C}$. On the other hand, the value of the interfacial tension calculated by the Choi-Schowalter model was about $3.5 \mathrm{mN} / \mathrm{m}$. This value is stable when the temperature increases from 180 until $220{ }^{\circ} \mathrm{C}$. The comparison of these results with an experimental value of interfacial tension $(6.25 \mathrm{mN} / \mathrm{m})$ obtained in the same conditions and deduced from the literature [37] indicates the existence of a slight difference. However, the Palierne model allows a prediction which is qualitatively in agreement with the experimental observations. 
http://wjst.wu.ac.th

\section{Conclusions}

In this work, the dynamic rheological behavior of polypropylene/polystyrene (PP3/PS) (30/70) was studied and determined by two mathematical models namely the models of Palierne and Choi-Schowalter. The predicted results were compared with those obtained from a previous experimental work.

The results found by the prediction of the two models showed that the rheological properties of blends depend on the nature of constituents. The presence of a shoulder on the curves of storage modulus $\left(G^{\prime}\right)$ shows the relaxation of the dispersed phase PP3 and the interface; this shoulder decreases with increasing temperature. The experimental data used in this study for comparison confirms that the Palierne emulsion model is able to describe quantitatively the linear viscoelastic properties of the blend.

In addition, it was shown that the obtained interfacial tension is not necessary accompanied by the reduction of the size of the dispersed particles, where the interface plays an important role in determining the rheological behavior. The difference in the values may be due to the used models. Moreover, the obtained values of interfacial tension are in the range of values reported in the literature for mixtures of similar polymers. We can, therefore, conclude that the model of Palierne is more accurate than the ChoiSchowalter equation in determining the rheological properties and interfacial tension.

According to this study, it is possible to model the rheological behavior of polymer blends as a function of viscoelastic properties of each component.

\section{References}

[1] J Parameswaranpillai, S Thomas and Y Grohens. Polymer Blends: State of the Art, New Challenges, and Opportunities. In: S Thomas, Y Grohens and P Jyotishkumar (Eds.). Characterization of Polymer Blends: Miscibility, Morphology, and Interfaces. $1^{\text {st }}$ ed. Wiley-VCH Verlag GmbH \& Co. KGaA, 2015, p. 1-6.

[2] LA Utracki. Polymer Alloys and Blends: Thermodynamics and Rheology. Hanser Publishers, Munich, 1990.

[3] TM Alam, JU Otaigbe, D Rhoades, GP Holland, BR Cherry and PG Kotula. Nanostructured polymer blends: Synthesis and structure. Polymer 2005; 46, 12468-79.

[4] Z Bai and $\mathrm{H}$ Guo. Interfacial properties and phase transitions in ternary symmetric homopolymercopolymer blends: A dissipative particle dynamics study. Polymer 2013; 54, 2146-57.

[5] O Sadiku-Agboola, ER Sadiku, AT Adegbola and OF Biotidara. Rheological properties of polymers: Structure and morphology of molten polymer blends. Mater. Sci. Appl. 2011; 2, 30-41.

[6] D Graebling, R Muller and JP Palieme. Linear viscoelastic behavior of some incompatible polymer blends in the melt: Interpretation of data with a model of emulsion of viscoelastic liquids. Macromolecules 1993; 26, 320-9.

[7] W Yu, W Zhou and C Zhou. Linear viscoelasticity of polymer blends with co-continuous morphology. Polymer 2010; 51, 2091-8.

[8] L Fernández-Espada, C Bengoechea, F Cordobés and A Guerrero. Linear viscoelasticity characterization of egg albumen/glycerol blends with applications in material moulding processes. Food Bioprod. Process. 2013; 91, 319-26.

[9] A Einstein. Investigation on Theory of Brownian Movement. Methuen, London, 1926.

[10] JG Oldroyd. The elastic and viscous properties of emulsions and suspensions. Proc. Roy. Soc. London 1953; 218, 122-32.

[11] SJ Choi and WR Schowalter. Rheological properties of no-dilute suspensions of deformable particles. Phys. Fluid 1975; 18, 420-7.

[12] JF Palierne. Linear rheology of viscoelastic emulsions with interfacial tension. Rheol. Acta 1990; 29, 204-14.

[13] M Bousmina and $\mathrm{R}$ Muller. Linear viscoelasticity in the melt of impact PMMA: Influence of concentration and aggregation of dispersed rubber particles. J. Rheol. 1993; 37, 663-79.

[14] D Graebling, D Froelich and R Muller. Viscoelastic properties of polydimethylsiloxanepolyoxyethylene blends in the melt: emulsion mode. J. Rheol. 1989; 33, 1283-91. 
http://wjst.wu.ac.th

[15] C Lacroix, M Aressy and PJ Carreau. Linear rheology of viscoelastic emulsions with interfacial tension. Rheol. Acta 1997; 36, 416-28.

[16] PJ Carreau, M Bousmina and A Ajji. Rheological Properties of Blends: Facts and Challenges. In: KP Ghiggino (Ed.). Progress in Pacific Polymer Science 3. Springer Verlag, New York, 1994, p. 25-39.

[17] C Kunyawut and HE Hermes. Rheological behavior of immiscible PS/LDPE blends: A comparative study of the Palierne emulsion model. Walailak J. Sci. Tech. 2015; 12, 1157-69.

[18] AIRomoscanu, MB Sayir, K Hausler and AS Burbidge. Rheological behavior of low-viscous emulsions and interpretation with a theoretical model. Colloid Surf. A 2003; 223, 113-33.

[19] C Friedrich, W Gleinser, E Korat, D Maier and J Weese. Comparison of sphere-size distributions obtained from rheology and transmission electron microscopy in PMMA/PS blends. J. Rheol. 1995; 39, 1411-25.

[20] C Lacroix, M Bousmina, PJ Carreau, BD Favis and A Michel. Properties of PETG/EVA blends: Viscoelastic, morphological and interfacial properties. Polymer 1996; 37, 2939-47.

[21] N Mekhilef, PJ Carreau, BD Favis, P Martin and A Ouhlal. Viscoelastic properties and interfacial tension of polystyrene-polyethylene blends. J. Polym. Sci. B 2000; 38, 1359-68.

[22] P Scholz, D Froelich and R Muller. Viscoelastic properties and morphology of two phase polypropylene/polyamide blends in the melt, Interpretation of results with an emulsion model. $J$. Rheol. 1989; 33, 481-99.

[23] W Gleinser, H Braun, C Friedrich and HJ Cantow. Correlation between rheology and morphology of compatibilized immiscible blends. Polymer 1994; 35, 128-35.

[24] S Jose, S Thomas, I Aravind and J Karger-Kocsis. Rheology of multiphase polymer blends with and without reactive compatibiliser: Evaluation of interfacial tension using theoretical predictions. Int. J. Plast. Tech. 2014; 18, 223-40.

[25] HA Khonakdar, SH Jafari and MN Hesabi. Miscibility analysis, viscoelastic properties and morphology of cyclic olefin copolymer/polyolefin elastomer (COC/POE) blends. Compos. B Eng. 2015; 69, 111-9.

[26] EJ Dil and BD Favis. Localization of micro- and nano-silica particles in heterophasepoly(lactic acid)/poly(butylene adipate-co-terephthalate) blends. Polymer 2015; 76, 295-306.

[27] MK Kwon and KS Cho. Analysis of the Palierne model by relaxation time spectrum. Korea Aust. Rheol. J. 2016; 28, 23-31.

[28] AW Birley, B Haworth and J Batchelor. General Chemical Resistance. Physics of Plastics, New York, Hanser, 1992, p. 488-92.

[29] SA Samsudin, A Hassan, M Mokhtar and SMS Jamaluddin. Progress in rubber, effect of SEBS on the mechanical properties and miscibility of polystyrene rich polystyrene/polypropylene blends. Plast. Recycl. Tech. 2005; 21, 261-76.

[30] PV Puyvelde, S Velankar and P Moldenaers. Rheology and morphology of compatibilized polymer blends. Curr. Opin. Colloid Interface Sci. 2001; 6, 457-63.

[31] BD Favis and JP Chalifoux. Influence of the composition on the morphology of polypropylene/polycarbonate blends. Polymer 1988; 29, 1761-7.

[32] S Hammani. 2013, Structuration Par Cisaillement et Rhéologie des Systèmes Polymères Complexes. Ph.D. Dissertation, University of Blida, Algeria.

[33] S Hammani, N Moulai-Mostefa, L Benyahia and JF Tassin. Effects of shear during the cooling on the rheology and morphology of immiscible polymer blend. IOP Conf. Series: Mater. Sci. Eng. 2014; 64, 012056.

[34] S Hammani, N Moulai-Mostefa, L Benyahia and JF Tassin. Effects of composition and extrusion parameterson the morphological development and rheological propertiesof PP/PC blends: Cocontinuity investigation. J. Polym. Res. 2012; 19, 9940.

[35] SS Dagli and KM Kamdar. Effects of component addition protocol on the reactive compatibilization of HDPE/PET blends. Polym. Eng. Sci. 1994; 34, 1709-19. 
http://wjst.wu.ac.th

[36] HS Lee and ES Kim. Linear viscoelasticity and the measurement of interfacial tension in apartially miscible polymer mixture. Macromolecules 2005; 38, 1196-200.

[37] PHP Macaúbas and NR Demarquette. Interfacial tension, morphology and linear viscoelasticity behavior of PP/PS blends. Polímeros 1999; 9, 71-7. 